\title{
Descrição de um novo gênero de Ochlerini Rolston (Heteroptera, Pentatomidae, Discocephalinae) ${ }^{1}$
}

\author{
Luiz Alexandre Campos 2,3 \\ Jocélia Grazia ${ }^{2,4}$
}

\begin{abstract}
Description of a new genus of Ochlerini Rolston (Heteroptera, Pentatomidae, Discocephalinae). The genus Similiforstona, gen.n. and its type species Similiforstona bella, sp.n. are described from Rondônia, Brazil. S. bella is based on a single female specimen. Similiforstona is very similar to Forstona Rolston, 1992 differing basically on the antennal structure.

KEY WORDS. Similiforstona, Similiforstona bella, new genus, new species, taxonomy.
\end{abstract}

Por ocasião da realização do trabalho de análise cladística da tribo Ochlerini (em preparação) verificou-se a existência de novos táxons; um deles é o gênero aqui proposto. Pelos resultados da análise Similiforstona posiciona-se em uma politomia que envolve também os gêneros Tetrochlerus Breddin, 1904 e Alathetus Dallas, 1851.

Foi examinada uma fêmea conservada a seco da coleção entomológica do Museu Nacional, Rio de Janeiro. A dissecação, o tratamento das genitálias e a confecção das ilustrações seguem CAMPOS \& GRAZIA (1995). A terminologia das peças da genitália está de acordo com DuPUIS (1970). Todas as medidas estão expressas em milímetros.

\section{Similiforstona gen.n..}

Espécie-tipo: Similiforstona bella sp.n..

Cabeça tão longa quanto larga, declivosa. Jugas mais longas que o clípeo, convergentes mas não se tocando no ápice; margem lateral sinuosa. Base das jugas junto aos olhos formando um pequeno dente subtriangular. Olhos levemente projetados lateralmente na região posterior; a largura de um olho equivalente a aproximadamente $1 / 5$ da largura da cabeça. Antenas com quatro segmentos, na seguinte proporção: primeiro ultrapassa levemente o ápice das jugas e é pouco maior que $1 / 3$ do segundo, terceiro equivale a $3 / 4$ do segundo, quarto igual ao terceiro. Búculas uniformemente elevadas, obtusas anteriormente e arredondadas posteriormente, não atingindo a base da cabeça. Origem do primeiro artículo rostral anterior à linha transversal imaginária tangente à margem anterior dos olhos; ápice sobre o prosterno.

1) Contribuição número 353 do Departamento de Zoologia, Universidade Federal do Rio Grande do Sul.

2) Departamento de Zoologia, Universidade Federal do Rio Grande do Sul. Avenida Paulo Gama, 90046-900 Porto Alegre, Rio Grande do Sul, Brasil.

E-mail: campos@portoweb.com.br ou jocelia@vortex.ufrgs.br

3) Bolsista FAPESP, processo 96/1328-2.

4) Bolsista CNPq. 
Pronoto declivoso adiante dos ângulos umerais; margem anterior profundamente escavada em "u" aberto, margens ântero-laterais levemente côncavas. Dentículos dos ângulos ântero-laterais pouco proeminentes, dirigidos lateralmente. Escutelo subtriangular, margens laterais constritas a $2 / 3$ do comprimento a partir da base; ápice estreitamente arredondado, atingindo o nível do quinto segmento do conexivo; ângulos basais negros, com pequenas fóveas. Hemiélitros pouco ultrapassando o ápice do abdome; ângulo apical do cório atingindo a metade do sexto segmento do conexivo; sutura claval alcançando o escutelo ligeiramente após a constrição desse; membrana com diversas veias transversais, formando células. Prosterno convexo, mesosterno e metasterno planos, percorridos por uma carena longitudinal mediana. Área evaporatória pouco rugosa, ocupando uma estreita faixa semilunar junto à margem posterior da mesopleura, mais larga junto à inserção da mesocoxa; ocupando uma área triangular na metapleura que atinge a metade do comprimento dessa, com a margem lateral externa sub-retilínea. Peritrema ostiolar auricular, reduzido, não atingindo a margem lateral externa da área evaporatória metapleural. Tíbias com sulco dorsal raso e largo delimitado por carenas laterais baixas; superfície lateral externa suavemente sulcada.

Conexivo exposto, ângulos póstero-laterais não desenvolvidos. Abdome com um sulco raso longitudinal mediano nos urosternitos alcançados pelo rostro. Base do terceiro urosternito desprovida de tubérculo mediano; tricobótrios externos à linha tangente aos espiráculos.

Genitália fêmea. Gonocoxitos 8 com bordos suturais justapostos. Laterotergitos $8 \mathrm{com}$ espiráculo conspícuo junto ao ângulo basal. Gonocoxitos 9 formando o pseudoesternito triangular, provido de carena longitudinal mediana. Laterotergitos 9 atingindo a banda que une os laterotergitos 8 , margens laterais internas dos laterotergitos 9 em ângulo obtuso, justapostas na metade posterior, ocultando o segmento $X$.

Comentários. De acordo com uma análise cladística de Ochlerini (em preparação), Similiforstona gen.n. posiciona-se em uma politomia que envolve também os gêneros Tetrochlerus e Alathetus; portanto, o seu correto relacionamento com esses táxons permanece incerto. Tal politomia é suportada pela condição de quatro artículos antenais. Com relação a Forstona Rolston, 1992, ambos os gêneros compartilham a forma peculiar das placas genitais, onde o bordo posterior dos gonocoxitos 8 projetando-se posteriormente, formando um assoalho, é um estado homoplástico para esses gêneros; diferem no número de artículos antenais, Forstona apresentando cinco artículos e Similiforstona, quatro.

Etimologia. Similiforstona, do latim similis (semelhante), relativo a ter uma aparência semelhante a Forstona.

\section{Similiforstona bella sp.n.}

Figs 1-4

Holótipo fêmea, BRASIL, Rondônia: Samuel (Rio Jamari), 4.V.1944, Parko leg. (depositado no Museu Nacional, UFRJ, Rio de Janeiro, Rio de Janeiro, Brasil) (Fig. 1). 


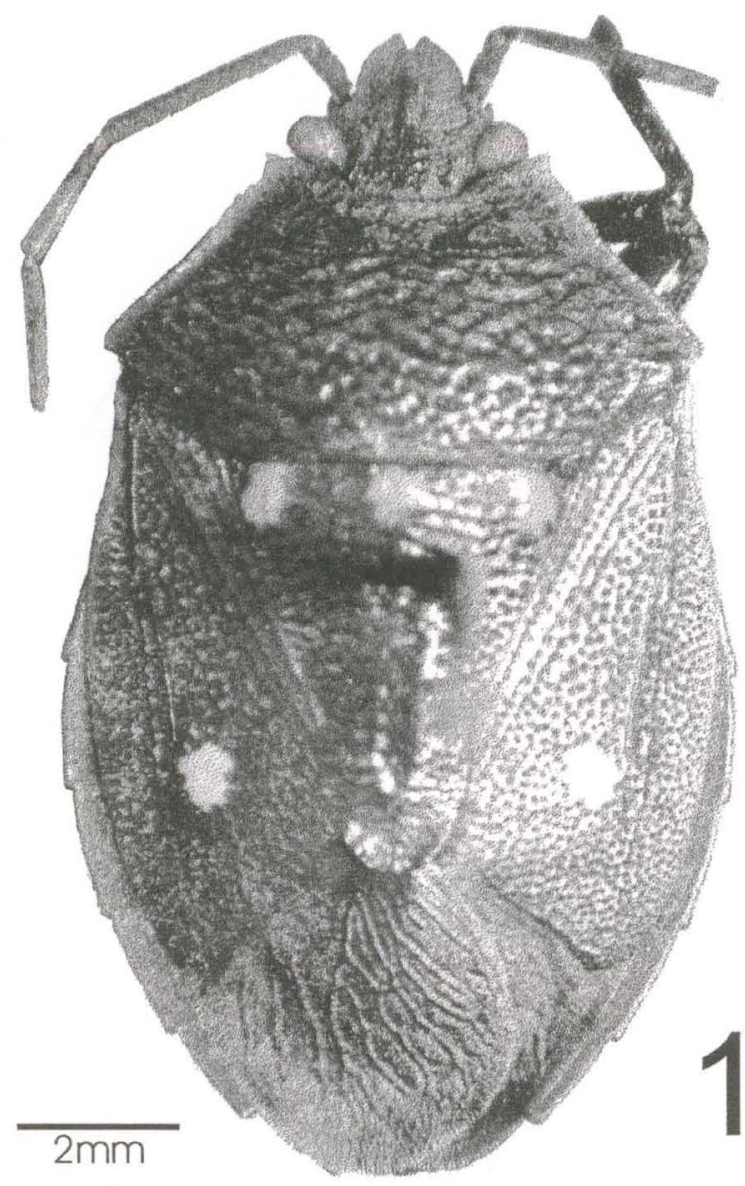

Fig. 1. Similiforstona bella sp.n., holótipo fêmea, dorsal.

Diagnose. Coloração geral marrom cúprea, pontuações negras. Corpo delineado por uma estreita faixa avermelhada nas margens ântero-laterais do pronoto, terço anterior do cório e conexivo; cabeça desprovida dessa faixa. Três máculas amareladas na base do escutelo e uma em cada hemiélitro, junto ao ápice da veia radial. Pernas enegrecidas.

Cabeça com a superfície rugosa, principalmente no vértice e na base das jugas. Pontuações negras, muitas vezes confluentes. Clípeo levemente convexo na região mediana. Ocelos posicionados próximos às margens laterais da cabeça, posteriores aos olhos. Artículos antenais I, II e III com pilosidade esparsa, os dois primeiros negros, o terceiro negro na metade basal e marrom claro na apical, IV densamente piloso e marrom-claro. Rostro marrom ferrugíneo; segundo segmento atingindo as mesocoxas, terceiro atingindo as metacoxas, quarto alcança a margem anterior do urosternito IV. 

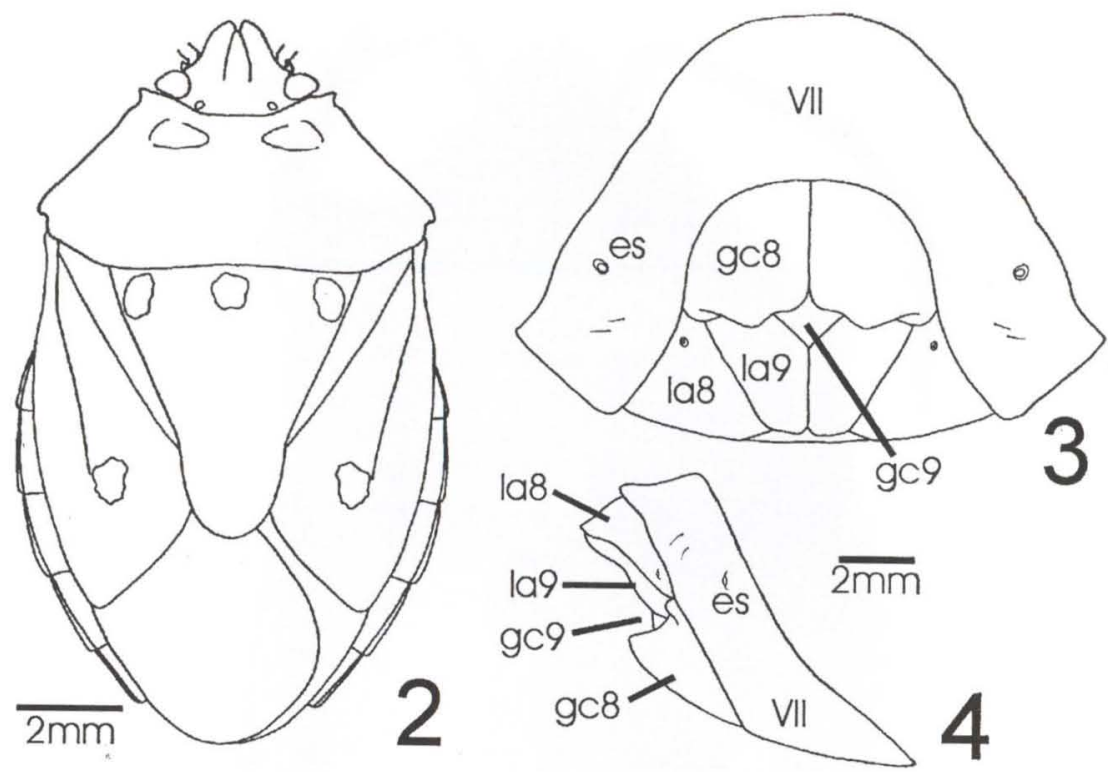

Figs. 2-4. Similiforstona bella sp.n., holótipo fêmea. (2) Contorno evidenciando as máculas no escutelo e hemiélitros, dorsal; (3) placas genitais, ventral; (4) placas genitais, lateral. (es) Espiráculo, (gc8) gonocoxito 8, (gc9) gonocoxito 9, (la8) laterotergito 8, (la9) laterotergito 9, (VII ) sétimo urosternito.

Pronoto levemente rugoso; pontuações maiores que as da cabeça e raramente confluentes. Cicatrizes marrom-escuras, pontuadas internamente exceto no ângulo interno e margem posterior, que se apresentam de aspecto aveludado. Margens ântero-laterais emarginadas e avermelhadas, suavemente rugosas. Ângulos umerais rombos, com emarginação anterior suave. Escutelo com pontuações semelhantes às do pronoto, mas diminuindo de tamanho junto ao ápice. Margem anterior com três máculas amarelo-escuras, uma mediana e uma junto a cada fóvea; cada mácula com aproximadamente o mesmo diâmetro de um olho (Figs 1,2); margens laterais apresentando uma ligeira deflexão delineada de negro junto ao ápice do escutelo. Hemiélitros com pontuações no endocório similares às do escutelo, mais densamente distribuídas e diminuindo de tamanho em direção às margens. Terço anterior da margem lateral externa do cório avermelhado. Mácula presente junto ao ápice da veia radial, de tamanho semelhante às do escutelo porém mais clara. Área evaporatória marrom-pálida. Pernas enegrecidas, a metade basal dos fêmures marrom-ferrugíneo.

Conexivo com pontuações pequenas na metade interna, iguais às menores dos hemiélitros, metade externa sem pontuações e avermelhada. Abdome ventralmente com coloração marrom-ferruginosa; região central desprovida de pontuações e com leve sulco longitudinal nos urosternitos III e IV. Área externa aos espiráculos cúprea com pontuações marrom escuras; margem lateral do abdome com uma estreita faixa avermelhada sem pontuações. 
Genitália fêmea (Figs 3, 4). Gonocoxitos 8 uniformemente convexos, exceto na margem posterior, que se projeta posteriormente como uma área intumescida mediana, formando um assoalho junto à base dos laterotergitos 9. Laterotergitos 8 subtriangulares, com a margem posterior convexa. Margem lateral externa dos laterotergitos 9 sub-retilínea, ápice arredondado.

Medidas. Comprimento dos artículos antenais: I 0,8, II 2,6, III 1,5, IV 1,9; cabeça: comprimento 2,2, largura 2,8; pronoto: comprimento 3,1, largura 7,0; escutelo: comprimento 4,7, largura 4,4; comprimento total: 12,9; largura abdominal: 7,9.

AGRADECIMENTOS. Agradecemos ao Dr. A. Lago pelo empréstimo do material.

\section{REFERÊNCIAS BIBLIOGRÁFICAS}

Campos, L.A. \& J. Grazia. 1995. Paratibraca, um novo gênero de Pentatomini (Heteroptera, Pentatomidae). Iheringia, Sér. Zool. (79): 163-171.

DUPUIS, C. 1970. Heteroptera, p. 190-208. In: S.L. TUXEN (Ed.). Taxonomist's Glossary of Genitalia of Insects. Copenhagen, Munksgaard, 359p.

Recebido em 16.XII.1999; aceito em 31.VIII.2000 